\title{
Medical Image of the week: Endobronchial Valves
}

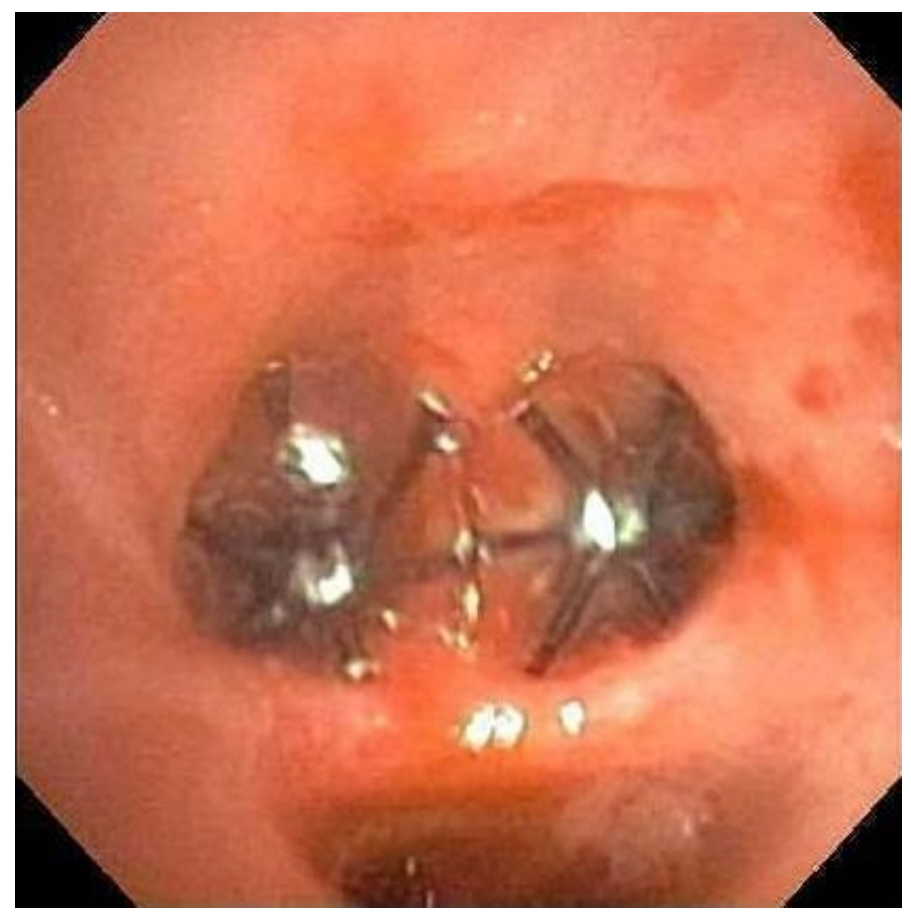

Figure 1. Bronchoscopic view of the endobronchial valves in the right upper lobe subsegments.

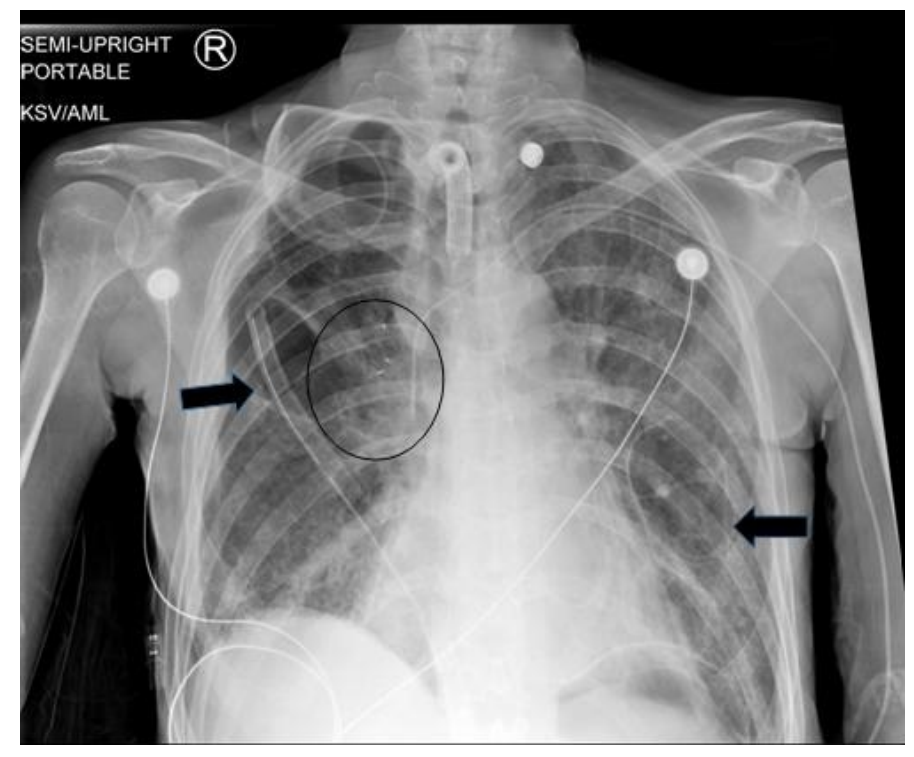

Figure 2. Post procedural chest x-ray shows the valves (encircled). Other findings on this chest $x$-ray include a tracheostomy tube, right sided chest tube, left sided PICC line. Bilateral pneumatoceles are also seen (arrows). 
A 39 year-old woman was referred to our hospital for evaluation of persistent bronchopleural fistula after severe necrotizing streptococcal pneumonia. She had undergone a segmentectomy for the necrosis resulting in the broncho-pleural fistula. Her overall medical condition and malnutrition precluded another major surgery such as a muscle flap for the persistent air leak. Endobronchial valve placement was attempted to minimize the gradient and leak across the parenchymal defect to promote healing.

A sequential balloon occlusion technique was used to localize the leak to the right upper lobe, which was the site of the previous surgery. The sub-segments were measured and three endobronchial valves (Spiration ${ }^{\circledR}$, Olympus Respiratory, USA) (1). Valves of 5 $\mathrm{mm}, 6 \mathrm{~mm}$ and $7 \mathrm{~mm}$ - were placed in the three sub-segments of the right upper lobe (Figure 1) with a flexible bronchoscope. Near elimination of the air leak was seen post procedure. Figure 2 shows post procedure chest x-ray showing the three valves.

Removable endobronchial valves have been shown to be safe and effective in cases of persistent post-operative air leaks (2).

Bhupinder Natt MD and James Knepler MD

Division of Pulmonary, Allergy, Critical Care and Sleep

Banner University Medical Center-Tucson

Tucson, AZ USA

\section{References}

1. Olympus Corporation. Spiration $₫$ valve system. Available at: http://www.spiration.com/us/product-overview (accessed 6/21/16).

2. Gillespie CT, Sterman DH, Cerfolio RJ, Nader D, Mulligan MS, Mularski RA, Musani Al, Kucharczuk JC, Gonzalez HX, Springmeyer SC. Endobronchial valve treatment for prolonged air leaks of the lung: a case series. Ann Thorac Surg. 2011 Jan;91(1):270-3. [CrossRef] [PubMed] 